The importance of epistemic cognition in student-centred learning.

\title{
The Issue
}

While the higher education literature asserts that student-centred learning is desirable, the nature of the knowledge and the range of instructional practices which tutors need in order to genuinely subscribe to student-centred learning are not well understood. Nor is it clear how students themselves see student-centred learning as being best supported. Student-centred learning may provide an orienting perspective, but it does not define particular teaching practices. Thus, while the idea of student-centred learning may lead us to question the adequacy of our teaching, we are nevertheless faced with the challenge of developing practices that are consistent with such a perspective. Significant pedagogical change involves reconstituting fundamental notions of teaching and learning in addition to inventing different kinds of opportunities for learning. It was against this background that a small scale study was undertaken to analyse the extent to which students' beliefs about the role of tutorials and of tutors in gaining knowledge were consistent with assumptions underpinning studentcentred learning.

\section{Introduction}

Higher education has long professed the aim of encouraging autonomous learning. However, its primary pedagogic method has traditionally been one of lecturing, note-taking and memorizing information for later recognition or reproduction, and while current lecturing practices might regularly incorporate various manifestations of 'buzz groups' (Brown \& Atkins, 1988) to engender cognitive engagement (Harvey \& Knight, 1996), the students' preconceptions of learning may neither include nor recognise the relevance of such activities (Prosser \& Trigwell, 1999) thus attenuating their pedagogic purpose. Lecturing is based on a model in which teaching is predominantly telling and showing. If we want people to know what we know, we tell them and/or show them. Unsuccessful teaching tends to be remedied by repeating the curriculum content, breaking the communication into smaller parts, and finding different ways to express the idea to be grasped. The model of learning on which this 
The importance of epistemic cognition in student-centred learning.

traditional teaching is based is a behavioural one that assumes knowledge to be some sort of commodity which can be passed from person to person in inert form.

More recently, the education community has begun to question this traditional view of learning. Instead, we now understand that people learn by being involved and by being active in the learning process, often working in collaboration with others. This view of learners as active constructors and organizers of their own learning has its origins in Piagetian theory where the learner's construction of knowledge is a self-regulating process. Individuals' cognitive schemes allow them to establish an orderliness and predictability in their experiential worlds. When experience does not fit with the individual's schemes, a cognitive disequilibrium results, which triggers the learning process. This disequilibrium leads to adaptation. Reflection on successful adaptive operations leads to new or modified concepts, contributing to re-equilibration. Thus from a constructivist perspective, knowledge is not passively received from the world, from others, or from authoritative sources. Rather, all knowledge is created as individuals (and groups) adapt to and make sense of their experiential worlds. This view of knowledge construction as individual and personal, and based on previously constructed knowledge is fundamentally different from that implied by behaviourism. Rather, constructivism implies that:

- learners are intellectually generative (with the capacity to pose questions, solve problems, and construct theories and knowledge) rather than empty vessels waiting to be filled;

- instruction should be based primarily on the development of learners' thinking;

- the locus of intellectual authority resides not in the teacher nor in the resources, but in the discourse facilitated by both teachers and learners.

However, while constructivism potentially provides powerful analytical tools to unpack the processes of learning, the historical dominance of behaviourism creates two related problems. Firstly is the pervasiveness of an educational system in the United Kingdom (and elsewhere) 
The importance of epistemic cognition in student-centred learning.

that increasingly emphasises public accountability, and that is clearly influenced by a behavioural model of learning. So not only has behaviourism been dominant, it continues insidiously to be influential. Secondly, obsessive concern with accountability may well mean that the ideology of behaviourism is accepted as dominant with the language of learning outcomes, objectives and achievements increasingly distorting teaching towards assessment. This can create a gradual marginalisation of those concepts which remain unexpressed and can lead to teaching which is purportedly reformed on constructivist principles but merely comprises practices which are grafted on to the questionable assumptions of a behavioural model of learning, thereby losing much of their potential to facilitate the intentional learning (Bereiter \& Scardamalia, 1989) which is so necessary for the knowledge economy in general and higher education in particular. But constructivism suggests that teaching should:

1. enable learners to build from previous constructions, errors and misconceptions;

2. attempt to integrate informal and formal knowledge;

3. make use of metacognition and strategic self-regulation by learners;

4. focus not just on the learner's cognitions, but on the learner's affect, beliefs and conceptions of knowledge;

5. emphasise the role of negotiated and shared meanings;

6. monitor the effects of discussion and collaboration on the learners' conceptions;

7. derive not just from the teacher's knowledge of subject matter and teaching skills, but from the teacher's beliefs, conceptions and personal theories about subject matter, teaching and learning.

What is central to all of these suggestions (Applefield et al, 2001) is the critical importance of discourse - the need for teachers to challenge and for learners to have to justify, reason or defend a position since it is reflection on one's own, and others', beliefs, assumptions and conceptions, that enables conceptual change on the part of learners to occur (Kuhn, 1992; Langer \& Applebee; 1987; O'Connor \& Michaels, 1996). Since knowledge is viewed as an 
The importance of epistemic cognition in student-centred learning.

ongoing creation of human minds rather than an aspect of the external world waiting to be discovered, teaching which is based on constructivist principles logically begins by establishing learners' conceptions, which vary according to one's developmental sophistication (Perry, 1970; King \& Kitchener, 1994) and according to beliefs about the organisation and stability of knowledge (Schommer, 1990; 1998). Furthermore, given that knowledge creation is viewed as productive and created through discourse (Bereiter, 2002), what seems important to ascertain is not the extent of disconnected propositional knowledge, nor the incidence of content-free critical thinking, but rather how learners understand the process of knowing and how they justify their beliefs which together constitute epistemic cognition or beliefs (King \& Kitchener, 1994). It was King \& Kitchener's (1994) thesis that one's epistemic cognition will be more or less sophisticated depending on the stage of reasoning that has been achieved; with the reasoning being dependent on how problematic a phenomenon is perceived to be. Further, perceiving a phenomenon to be problematic is predicated on assumptions about the nature of knowledge and how it is acquired. Given the lack of evidence on the quality of epistemic cognition, the study reported here is limited to describing a small sample of student teachers' epistemic beliefs.

Although a very small scale study, the results may nevertheless be of considerable interest, for two reasons. At a general level some delineation on the incidence of epistemic cognition seems important if practice in higher education is to encourage autonomous learning, particularly in view of the finding that espoused and observed practices do not always match (Bowden \& Marton, 1998; Murray \& Macdonald, 1997). At the more specific level of teacher education the need for some taxonomy of progress in epistemic cognition is equally important. Student teachers do not embark on teacher education courses as blank slates (LaBoskey, 1993) but bring with them a vast array of personal theories about teaching, learning and learning to teach (John, 1996). In spite of the rhetoric to the contrary (O'Hear, 1988; The Hillgate Group, 1989; Lawlor, 1990), it is not at all clear that preservice field experience of itself does anything other than confirm to novice student teachers their own 
The importance of epistemic cognition in student-centred learning.

prejudices and biases. What this highlights is the importance of reflective judgement in order that the students' learning may be faster, richer and necessarily generalisable in the finite time of a preservice course. For both general and specific reasons, then, it is seen as important to try to characterise epistemic cognition so that it may be possible to facilitate its development through appropriate instructional activities. In summary, the aim of this study is to determine the extent of epistemic cognition in a sample of student teachers through a content analysis of their views on the role of tutorials and of tutors in gaining knowledge.

\section{Method}

\section{Design}

Because of the desire to access students' epistemic beliefs (for the purpose of better understanding what a constructivist pedagogy might entail) it was deemed important that participants provided an extended response to the stimulus task. While the interview is often used in critical-thinking research to probe participants' justifications, the researchers in this study were persuaded by the need for a task requiring a prepared written response which would allow participants to express their considered views and enable them to transform extant and earlier understanding(s) into something more sophisticated (Bereiter \& Scardamalia, 1987; Langer \& Applebee, 1987; Wells, 2002). Because a writing task was likely to reflect the most advanced level of understanding the participants were able to express, the stimulus task probed epistemic cognition through inviting free-responses to a number of statements about the role of tutorials and of tutors in gaining knowledge. In accessing epistemic cognition King \& Kitchener (1994) suggest that desirable features of the stimulus task include:

- a focus on ill-structured problems which involve doubt about the adequacy of one's current understanding of an issue since only when faced with real problems do people engage in true reflective thinking; 
The importance of epistemic cognition in student-centred learning.

- a requirement to give reasons for the content of responses since it is the reasons that can reveal the sophistication of the thinking through, for example, relating directly to the evidence or to the source of the information;

- the use of generally familiar knowledge since this allows participants to respond to issues about which they have some working knowledge and increases the participants' comfort with the task.

Using this guidance, it was reasoned that teacher education students' knowledge of teaching would be a fertile area from which to infer their epistemic beliefs partly because of its intrinsic interest to the participants (assumed from the fact that they were undergoing a degree level course in primary education) and partly because of their extensive personal experience of the formal education system. The content of the baseline stimulus list clustered on the role of tutorials and of tutors in gaining knowledge since the literature suggests these to be significant structural mechanisms to promote discourse and influence conceptual learning (Anderson, 1997; Brookfield \& Preskill, 1999, Rowland, 2000). The content was also judged to be general knowledge with which students in higher education could reasonably be expected to be familiar, given its focus in student evaluations (Lyon \& Hendry, 2002; Spencer \& Schmelkin, 2002; Byrne \& Flood, 2003).

\section{Participants}

A sample of 25 teacher-education students registered for a psychology module participated in the study during class attendance. The students, from a Scottish university, participated by invitation and had been randomly selected from the University's cohort of second-year Bachelor of Education students. The entire cohort $(n=120)$ had been participating in a series of small scale action research projects designed to inform learning and teaching policy/developments within the university's Education Faculty and so were not unfamiliar with the concerns of the researchers to elicit student perceptions. 
The importance of epistemic cognition in student-centred learning.

\section{Instrumentation}

Participants were asked to choose one or two statements from the baseline stimulus list (see Table 1, below) with which they either agreed or disagreed and to explain the reasons they had for holding their particular point(s) of view. In being asked to justify their views it was hypothesised that participants would demonstrate whether expressed preferences were a function of one's specific and necessarily limited experiences, one's interpretation of an expert's point of view or one's systematic/critical evaluations of data (King \& Kitchener, 1994). Justifications, in turn, are predicated on views of knowledge which range from existing absolutely and concretely to being the outcome of a process of reasonable enquiry. From the justifications offered it was therefore assumed that participants' views of knowledge might be inferred as non-problematic, as inherently and inexorably problematic or constructed through inquiry and evaluation (King \& Kitchener, 1994). To make the task as accessible as possible, it was also suggested that participants might want to contextualise their comments and if so that they should use the module for which they were currently registered, entitled Learners and Learning. Participants' justifications could then be mapped on to King \& Kitchener's (1994) stages of reasoning which are believed to have applicability to views of knowledge activated in "everyday educational settings" (Hofer \& Pintrich, 1997, p.103). Analysis

Content analysis was conducted through firstly reading and re-reading participants' responses to get a sense of what the texts seemed to be suggesting. Thereafter the recording units (Krippendorff 1980) were identified. These recording units may be otherwise known as segments, incidents or analysis units and in this study were determined semantically (Tesch, 1990). A meaning unit (Tesch, 1990) "is a segment of text that is comprehensible by itself and contains one idea, episode or piece of information" (p. 116). Such meaning units could be found either standing alone as in the reason tutors should meet the students' emotional needs or embedded in more extended text which needed disaggregation as in 
The importance of epistemic cognition in student-centred learning.

Tutorials are worthwhile when they help me to acquire academic skills because I gather that students are not very good at this (first semantic segment) so it seems logical that tutorials should help us to acquire this skill (second semantic segment). In other modules this skill is not covered so it is only in Learners and Learning that it is needed (third semantic segment). This is a very difficult skill to learn because the other modules are saying, 'learn these facts and you will be all right' (fourth semantic segment).

Meaning units which implied some view of the nature of knowledge were allocated to a stage of reasoning according to the system below, which is derived from King \& Kitchener (1994). Although King \& Kitchener (1994) outline seven stages of development in reasoning, they group these into the three broad categories of pre-reflective, quasi-reflective and reflective thinking. To manage this analysis in as straightforward a way as possible (albeit at the expense of richness of detail), only these three broad categories of thinking were used.

\section{Category System}

Pre-reflective thinking implies that:

- knowledge is either absolute or is temporarily uncertain - but will become certain when enough data are available;

- $\quad$ knowledge from 'good' authorities is 'right';

- others will not have different views of the same issue;

- justification is about showing that one's own beliefs are right, by stating them;

- evidence is unnecessary.

Quasi-reflective thinking implies that

- knowledge is not absolute and uncertainty is not just temporary;

- knowing is idiosyncratic to an individual - thus judgement is idiosyncratic to the person making it;

- evidence is necessary but need not be evaluated and is chosen to fit own beliefs; 
The importance of epistemic cognition in student-centred learning.

- rules of inquiry for the context have been invoked.

Reflective thinking implies that:

- knowledge is not a 'given' but must be actively constructed - the spectator view of the knower that characterised earlier stages will no longer suffice;

- knowledge is uncertain and claims of knowledge must be understood in relation to the context in which they were generated;

- beliefs are justified probabilistically on the basis of a variety of interpretative considerations, such as the weight of the evidence, the explanatory value of the interpretations, the risk of erroneous conclusions, the consequences of alternative judgments, and the interrelationships of these factors;

- conclusions should remain open to re-evaluation.

After initial attempts by the researchers to classify meaning units (Tesch, 1990) in the participants' writing a reliability check was conducted by asking three other coders to assign meaning units selected at random from the writings to the categories drafted by the researchers. The reliability levels achieved were acceptable (Kappa coefficients ranged from .82 to .92$)$. A research assistant used the final category system to code all the responses. Cronbach's alpha was used to calculate the reliability of the coding scheme. The results indicated that the coding could be carried out reliably over a two-week period. (Cronbach's alpha $=0.70)$.

\section{Results}

The purpose of the study was to discern students' epistemic beliefs. Collectively, all of the ideas in the baseline stimulus task were selected. The responses indicated agreement with all of the suggested roles of tutorials in gaining knowledge, namely to:

- share ideas so that each student has more ideas

- help student to understand the module material more fully

- acquire academic skills such as how to discus, analyse or evaluate an issue 
The importance of epistemic cognition in student-centred learning.

- better understand assessment requirements

- build and extend thinking on issues in the module

and with two of the suggested roles for tutors, namely to:

- explain module material which is unclear

- direct what happens in tutorials towards assessment requirements.

There was however, disagreement with the suggestion that tutors should give students autonomy to manage their own tutorials.

Inspection of the data revealed no responses corresponding to reflective thinking as described in King and Kitchener's (1994) stages of reasoning. Thus, only the categories of prereflective and quasi-reflective thinking were used. The most striking aspect of the analysis is that out of a total of 129 recording units nearly 40 percent of statements had most of the features of pre-reflective thinking. In almost all of the responses coded as pre-reflective thinking the participants implied that justification is about showing that one's own beliefs are right and that this is achieved by simply stating them.

Often the responses included a recommendation that the tutor should tell 'exactly how' to perform a specific task 'properly' with no indication that the performance might be problematic. Examples of responses categorised as pre-reflective included:

- $\quad$ some of the ideas are quite abstract and confusing and the tutor should be able to clarify everything and make connections between the reading and lectures

- obviously students weren't told how to answer the questions last year as there were no examples of good analysis

- I needed constantly reassured from the tutor that I am developing my knowledge about it properly

- the tutor should help guide students in the right way, as they may not be going in the right direction and therefore the task would have been a waste of time 
The importance of epistemic cognition in student-centred learning.

Most of the responses which were categorized as quasi-reflective thinking (61.2\%) attracted this classification on the grounds that they implied that knowledge is not absolute. One feature of quasi-reflective thinking which was absent altogether from responses was any attempt to use rules of inquiry for the context. What distinguishes quasi-reflective thinking from more fully reflective thinking for King and Kitchener (1994) is that, for the quasireflective thinker, knowing is idiosyncratic to an individual. Almost all the responses categorized as quasi-reflective thinking implied that judgement is idiosyncratic to the person making it. Another feature of this level of thinking is that people know that evidence is necessary, although they do not understand, as they do at the next level, that it needs to be evaluated. Often the participants' responses included the idea that rehearsing a range of ideas is helpful but there is no recognition that ideas need to be examined in the light of criteria. Examples of responses categorised as quasi-reflective included:

- highlights different points of view

- listening to others could give insight into a range of opinions

- by discussing with other students, and the tutor at times, come to an understanding of the module issues and iron out what effect these issues could have on the bigger picture

- tutorials are worthwhile when we discuss issues in the lecture, the book and from other people

- different opinions on how to answer the question, and why, should be discussed

- not all students will interpret the material in the same way

In almost all the responses categorized as quasi-reflective thinking, personal experience was invoked in support of their beliefs. According to King and Kitchener (1994) a central feature of this level of thinking is that evidence is chosen to fit their own beliefs. It is disappointing that no more than personal experience was offered in justifications given. 
The importance of epistemic cognition in student-centred learning.

One striking omission from the responses is that there are no probabilistic elements in justifications offered by any of the participants. According to King and Kitchener (1994) a central aspect of reflective thinking is that beliefs or recommendations are justified probabilistically on the basis of a variety of interpretative considerations, such as weighing evidence against criteria, explanatory value of interpretations, risk of erroneous conclusions, consequences of alternative judgments, utility of solution, possibility of successful implementation, need for action. Although the utility of proposed solutions and need for action appeared in many responses, these considerations were presented not in the context of justifying recommendations probabilistically but as absolute knowledge. For example, many respondents justified their disagreement with the proposal that students should have autonomy to manage their own tutorials by saying that, if this were to happen, there would no role at all for academic staff. These responses seem to imply lack of understanding that tutors might facilitate students' learning by, for example, setting up thought provoking tasks. In disagreeing with the proposal that students should have autonomy to manage their own tutorials no student considered an alternative of trying out and evaluating the consequences of more autonomy, nor did they weigh up their anecdotal evidence that some students do not respond well to autonomy against a possibility that a significant majority might be sufficient to make autonomy work. In a few cases participants wrote statements which contradicted each other, implying that the act of writing the first statement had created sufficient disequilibrium to cause a change in view. One of two participants, who wrote four times the average number of quasi-reflective statements, had no pre-reflective responses and the other had just one pre-reflective response, suggesting that quasi-reflective thinking was more securely established. That some participants had not started to move towards the next level is suggested by the finding that those who wrote four times the average number of pre-reflective responses wrote no quasi-reflective responses. However, any content analysis involves some degree of subjectivity in interpreting text. Statements which were difficult to classify were ambiguous statements such as by discussing the module material students will be able to put forward their views and opinions because it was difficult to decide if the participant believed 
The importance of epistemic cognition in student-centred learning.

that different views were absolute and equally acceptable or whether further reflection on and discussion about different views would result in their veracity being evaluated against a range of criteria. It was decided on balance to allocate to the quasi-reflective category any statements which implied that students should try to construct meanings for the criteria that had been issued at the beginning of the module. For example, the following statement was allocated to the quasi-reflective level because it followed a description of a tutorial discussion about what might count as analysis: before this we were unsure what was expected in the exam.

\section{Implications}

One interpretation of the students' responses is that they viewed the process of learning as something that was developmentally unavoidable and was 'done' to them, and viewed tutorials as the provision of simplified explanations of content, which were delivered by the tutor in a logical and structured fashion while at the same time minimising the potential for student error. This naïve view of learning is powerfully illuminated in these responses which negate or at least attenuate a more constructivist perspective. For example, in none of the responses was there any suggestion that learning involves challenge to existing conceptual frameworks to provoke the construction of more elaborate ones. While some participants thought it desirable that they extend their thinking in tutorials, they also made clear that it was achieved by the tutor going into content in more depth; giving examples; and going over module material. While students recognised that their own ideas might be slight in number, they saw this as being solvable through others' further ideas rather than critiquing extant ones. The students' lack of clarity on the importance of analysis and discussion suggests that they did not recognise the potential power of knowledge as transformative.

A second way in which the students' views discount a constructivist perspective is in their lack of willingness to engage with their own learning. Of those who responded to the statement that the tutor's role is to give students autonomy, all dismissed the proposal (if the tutor encourages students to decide on what is to be done during tutorial time that leaves too 
The importance of epistemic cognition in student-centred learning.

much to the students; the tutorials then become a debating session where you are forced into speaking), implying learning to be a passive, inevitable process in which the acquisition of new knowledge is without reference to existing cognitive beliefs and behaviour (Kember 2001). This in turn implies a lack of awareness of the need to monitor and regulate one's own learning. While metacognition need not invariably lead to learning (insofar as our individual reflections on our own cognitive and strategic processes may merely confirm that there is nothing we can do to improve our learning), it is nevertheless a necessary condition for successful learning (Hacker, 1998) since it enables the appropriate encoding and representation of information which is so essential to any kind of subsequent knowledge manipulation (Davidson \& Sternberg, 1998). As has been argued above, it is only when students appreciate that knowledge is an 'object' or 'series of objects' to be manipulated, reviewed, developed or discarded that they can genuinely engage with their own learning. What these examples seem to point to is a lack of intentional learning on the part of the students in this study. Intentional learning is goal-directed behaviour in which the learner not only attends to the specific requirements of the task but also generalises from the specifics of the task to derive underlying principles and thereby elaborate extant understanding in order to promote personally determined learning (Bereiter \& Scardamalia, 1989). While it is disappointing to note that the students in this study appeared unaware of the transformative potential of knowledge and so appeared not to invoke intentional learning, the phenomenon of enacting task requirements at a surface level only is a significant feature of higher education and is consistent with the now common finding that many students view support for their learning as emanating from a transmission model of teaching (Eraut, 1994).

Analyses of the data show that while students differed in their stages of reasoning, none were deemed to be at the most sophisticated level of reflective thinking. Although sophistication in levels of thinking increases as a function of age and education (King \& Kitchener, 1994), the findings in this study are consistent with the evidence that reflective thinking is achieved largely by advanced graduates studying at doctoral level (Hofer \& Pintrich, 1997). If it is 
The importance of epistemic cognition in student-centred learning.

indeed the case that reflective thinking is evidenced in only some rarefied minority, persons with naïve epistemic beliefs may be unable to understand and use sophisticated lines of reasoning. The implication of this for teaching in higher education is that students come to classes with different, and possibly underdeveloped, levels of epistemic competence and so need to learn to engage in more complex reasoning. On the basis of the findings of the study reported here, the development of more sophisticated reasoning would appear to require a two-pronged approach.

Firstly, rather than being concerned with teachers' presentational or performance skills, which cannot of themselves engender the level of cognitive engagement needed by students to become autonomous, teaching should be concerned with stimulating students to ascertain and resolve, for themselves, what is epistemically confusing or problematic. However, teaching practices which are consistent with the transmission model so valued by the students may be distinctly unhelpful in this endeavour. If tutors are perceived by students to be the inevitable authority on 'correct' knowledge, and if tutors acquiesce to this perception in what they say and do, they may well be perpetuating students' reluctance to make sense of ideas and analyse arguments for themselves. In order that clearly articulated reasoning from students be the focus of the teaching and learning endeavour, it is important that both students and tutors appreciate that it is students who must do the thinking. This emphasis on the students' cognitive engagement suggests that students need to be engaged in tasks for which they are individually and corporately accountable since a well designed accountability system can enable students to explain their thinking and the progress of such thinking (Brophy, 2002). Only by expecting (and rewarding) students to be accountable for their own goal achievements is there any possibility of moving students beyond the surface level engagement which is now so well documented in the literature.

A second approach to extending students' reasoning is to make the issue of what counts as evidence an explicit feature of course design. Rather than treating students' reasoning as general and transferable and as developing incidentally, course design needs to focus on what 
The importance of epistemic cognition in student-centred learning.

for students may be difficult ideas (King \& Kitchener, 1994). That there can be more than one perspective on an issue, that facts and their interpretations need to be distinguished, that opinions on an issue need to derive from careful interpretation of evidence, that legitimate differences of opinion exist on some issues and that evidence offered in substantiation can be open to evaluation all seem important in enabling a reasoned point of view to be elaborated and allowing reasoned choice or preference to be expressed amongst competing perspectives.

\section{Conclusion}

A sample of 25 undergraduate students completed a free-response task in which they were asked to give reasons for their agreement or disagreement with a small number of beliefs about the role of tutorials and of tutors in gaining knowledge. The analysis of participants' responses, according to King \& Kitchener's (1994) stages of reasoning, showed that their epistemic thinking was either at the stages of pre-reflective or quasi-reflective thinking with none exhibiting reflective thinking. The lack of reflective thinking suggests that the participants are unable to understand and use sophisticated lines of reasoning, a conclusion that is of concern given the increasing proliferation of knowledge and the need to be able to evaluate this knowledge in what is becoming a knowledge-based society (Bereiter, 2002). The findings have two main pedagogical implications: first that good teaching be understood not as a set of performance skills which may only be opportunistically related to students' extant conceptualisations but as the locus through which students confront their own epistemic beliefs. A second implication is that to extend students' reasoning, teaching practices must focus explicitly on the difficult issue of what counts as evidence. An explicit pedagogical focus on these ideas is called for since the levels of reflective thinking evidenced in this study are consistent with the finding that the concept of genuine evidence in everyday thinking is limited (Kuhn et al,1988; Kuhn, 1991). In addition to course design instantiating the nature and role of evidence, opportunities for frequent practice in working with and revisiting evidence are also called for since the internalisation of evidence-based reasoning would depend on habituation (Brophy, 2002). 
The importance of epistemic cognition in student-centred learning.

Overall, if student-centred learning is to grow, students need to be socialised to ask genuine questions and to rely on themselves and their peers as resources in solving the problems they identify. Pedagogical approaches which aim to support students in such endeavour must therefore seriously appraise the extent to which the transmission model is an appropriate one for teaching in higher education and the extent to which student-centred discussion activities or hands-on learning activities are sincerely or superficially similar to the pedagogical practices of tutors who genuinely subscribe to a constructivist view of learning. At the moment the issue is not well understood.

\section{References}

Anderson, C. (1997). Enabling and shaping understanding through tutorials. In F. Marton, D. Hounsell \& N. Entwistle, eds, The Experience of Learning, pp.184-197. Edinburgh: Scottish Academic Press.

Applefield, J. Huber, R. \& Moallem, M. (2001) Constructivism in theory and practice: toward a better understanding, High School Journal, 84, pp. 35-53.

Bereiter, C. \& Scardamalia, M. (1989). Intentional learning as a goal of instruction. In L. Resnick, ed, Knowing, Learning and Instruction, pp.361-392. Hillsdale, New Jersey:

Lawrence Erlbaum Associates.

Bereiter, C. (2002) Education and Mind in the Knowledge Age. Mahwah, New Jersey: Lawrence Erlbaum Associates.

Bowden, J. \& Marton, F. (1998). The University of Learning. London: Kogan Page.

Brookfield, S. \& Preskill, S. (1999). Discussion as a Way of Teaching. Buckingham: The Society for Research into Higher Education \& The Open University Press.

Brophy, J. (2002). Social Constructivist Teaching: Affordances and Constraints. Oxford: Elsevier Science Ltd.

Brown, G. \& Atkins, M. (1988) Effective Teaching in Higher Education. London: Routledge. 
The importance of epistemic cognition in student-centred learning.

Byrne, M. \& Flood, B. (2003) Assessing the teaching quality of accounting programmes: and evaluation of the course experience questionnaire. Assessment and Evaluation in Higher Education, 28(2) 135-45.

Davidson, J. \& Sternberg,R. (1998). Smart problem solving: how metacognition helps. In D. Hacker, J. Dunlosky \& A. Graesser, eds, Metacognition in Educational Theory and Practice, pp.47-68. Mahwah, New Jersey: Lawrence Erlbaum Associates.

Eraut, M. (1994). Developing Professional Knowledge and Competence. London: The Falmer Press.

Hacker, D. (1998). Definitions and empirical foundations. In D. Hacker, J. Dunlosky \& A. Graesser, eds, Metacognition in Educational Theory and Practice, pp.1-24. Mahwah, New Jersey: Lawrence Erlbaum Associates.

Harvey, L. \& Knight, P. (1996) Transforming Higher Education. Buckingham: The Society for Research into Higher Education \& The Open University Press.

Hillgate Group (1989) Learning to Teach. London: Claridge Press.

Hofer, B. \& Pintrich, P. (1997). The development of epistemological theories: beliefs about knowledge and knowing and their relation to learning. Review of Educational Research 67(1): 88-140.

John, P. (1996). Understanding the apprenticeship of observation in initial teacher education. In G. Claxton, T. Atkinson, M. Osborn, \& M. Wallace, eds, Liberating the Learner, pp.90107. London: Routledge.

Kember, D. (2001). Beliefs about knowledge and the process of teaching and learning as a factor in adjusting to study in higher education. Studies in Higher Education 26(2): 205-221. King, P. \& Kitchener, K. (1994). Developing Reflective Judgement. San Francisco: JosseyBass Publishers.

Krippendorff, K. (1980) Content Analysis. London: Sage Publications.

Kuhn, D. Amsel, E \& O'Loughhlin, M. (1988). The Development of Scientific Thinking Skills. London: Academic Press.

Kuhn, D. (1991). The Skills of Argument. New York: Cambridge University Press. 
The importance of epistemic cognition in student-centred learning.

Kuhn, D. (1992). Thinking as argument, Harvard Educational Review, 62, 155-78

LaBoskey, V. (1993) A conceptual framework for reflection in preservice teacher education.

In: J. Calderhead \& P. Gates, eds, Conceptualising Reflection in Teacher Development, pp.23-38. London: Falmer Press.

Langer, J. \& Applebee, A.(1987). How Writing Shapes Thinking, Urbana, IL: National Council of Teachers of English.

Lawlor, S (1990) Teachers Mistaught: training in theories or education in subjects? London:

Centre for Policy Studies.

Lyon, P. \& Hendry, G. (2002) The use of the course experience questionnaire as a monitoring evaluation tool in a problem-based medical programme. Assessment and Evaluation in Higher Education, 27(4) 339-52.

Murray, K. \& Macdonald, R. (1997). The disjunction between lecturers' conceptions of teaching and their claimed educational practice. Higher Education 33: 331-349.

O'Connor, M \& Michaels, S. (1996) Shifting participant frameworks: orchestrating thinking practices in group discussion, in: D. Hicks(Ed.) Discourse, Learning and Schooling. Cambridge: Cambridge University Press.

O’Hear, A. (1988) Who Teaches the Teachers? London: Social Affairs Unit.

Perry, W. (1970). Forms of Intellectual and Ethical Development in the College Years. New York: Holt, Rinehart and Winston.

Prosser, M. \& Trigwell, K. (1999). Understanding Learning and Teaching. London: Society for Research into Higher Education.

Rowland, S. (2000). The Enquiring University Teacher. Buckingham: The Society for Research into Higher Education \& The Open University Press.

Schommer, M. (1990). Effects of beliefs about the nature of knowledge on comprehension. Journal of Educational Psychology 82 (3): 498-504. 
The importance of epistemic cognition in student-centred learning.

Schommer, M. (1998). The role of adults' beliefs about knowledge in school, work and everyday life. In M. C. Smith \& T. Pourchot, eds, Adult Learning and Development, pp.127144. Mahwah, New Jersey: Lawrence Erlbaum Associates.

Spencer, K. \& Schmelkin, L. (2002) Student perspectives on teaching and its evaluation. Assessment and Evaluation in Higher Education, 27(5) 397-409.

Svensson, L. (1977). On qualitative differences in learning: III - study skill and learning. British Journal of Educational Psychology 47: 233-43.

Tesch, R. (1990). Qualitative Research: Analysis Types and Software Tools. London: Falmer Press.

Wells, G. (2002) Learning and teaching for understanding: the key role of collaborative knowledge building. In J. Brophy (Ed.) Social Constructivist Teaching: Affordances and Constraints,pp.1-41. Oxford: Elsevier Science Ltd. 
The importance of epistemic cognition in student-centred learning.

$\underline{\text { Table I Baseline Stimulus Task }}$

$\underline{\text { Instructions }}$

The following ideas represent some people's views about the role of tutorials and of tutors in gaining knowledge. Please choose one or two statements with which you either agree or disagree and explain your reasons for your point of view, taking account of the following two points.

1. In giving your reasons you might consider whether your view is due to your own experiences as a student, from your knowledge of the research evidence or whether your view is consistent with that of an expert.

2. If you want to contextualise any of your ideas please do so in relation to the module entitled, Learners and Learning

The role of tutorials in gaining knowledge is to help students to:

- $\quad$ share ideas so that each student has more ideas

- understand the module material more fully

- acquire academic skills such as how to discus, analyse or evaluate an issue

- better understand assessment requirements

- build and extend thinking on issues in the module

The role of tutors in gaining knowledge is to

- explain module material which is unclear

- direct what happens in tutorials towards assessment requirements

- give students autonomy to manage their own tutorials

Table II Percentage of responses and means allocated to each of two stages of reasoning

\begin{tabular}{|l|l|l|}
\hline Level of thinking & Percentage of responses & Mean number per participant \\
\hline Pre-reflective & 38.8 & 1.74 \\
\hline Quasi-reflective & 61.2 & 2.74 \\
\hline
\end{tabular}

